\title{
OVERVIEW ON THE DEVELOPMENT AND EVOLUTION OF EARTH OBSERVATION RESEARCH AND APPLICATIONS PROGRAMMES FOR AGRICULTURE AND ENVIRONMENT DURING THE LAST THREE DECADES IN ROMANIA
}

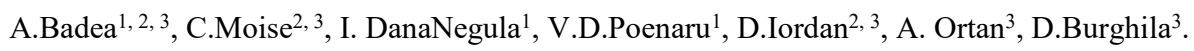 \\ 1: Romanian Space Agency, 21-25 Mendeleev St., 010362 Bucharest, Romania - (alexandru.badea, dana.negula, \\ violeta.poenaru)@rosa.ro; 2: Romanian Society of Photogrammetry and Remote Sensing, Bulevardul Lacul Tei 124, 020396, Bucharest \\ Romania- (chair.srft, trez.srft)@srft.ro; 3: University of Agronomic Sciences and Veterinary Medicine of Bucharest, 59 Bulevardul \\ Marasti, 011464 Bucharest, Romania - (cristian.moise, iordandaniela5, dburghila)@gmail.com, alina_ortan@hotmail.com
}

KEY WORDS: Earth Observation, Capacity Building, Space strategy, Remote Sensing, Sustainable Development Goals \begin{abstract}
Following the fall of communism in 1989, the R\&D sector started a modernization process. By establishing in 1995 a structure dedicated to the space activities - Romanian Space Agency (ROSA) - the Government recognized the importance of this innovative strategic domain. The National Space Strategy defined by means of the RTD policy, with effects on both academia and industry, had three objectives since the 90's: Participation to international space missions and programmes, Development of specific national projects and Capacity building at national level. In time, the experience acquired in the implementation of CIS, LCCS and LPIS/IACS projects offered the possibility to establish new certitudes for the evolution of the domain. The main development directions had been oriented towards the implementation of dedicated applications to answer problematics concerning smart agriculture, traceability, better agro-environmental practices and the relation with other scientific domains (e.g. cultural heritage). The partnership between a strong Governmental R\&D structure - ROSA- and the University of Agronomic Sciences and Veterinary Medicine of Bucharest (USAMVB) demonstrates the capacity to find solutions for promoting space EO technologies and adapt the higher education curricula in synergy with the development of the ambitious European space programme evolution.
\end{abstract}

\section{INTRODUCTION}

Following the fall of communism in 1989, the R\&D sector started a modernization process. By establishing in 1995 a structure dedicated to the space activities - Romanian Space Agency (ROSA) - the Government recognized the importance of this innovative strategic domain. The National Space Strategy defined by means of the RTD policy, with effects on both academia and industry, had three objectives since the 90's: Participation to international space missions and programmes, Development of specific national projects and Capacity building at national level. ROSA is an independent public organization legally mandated to coordinate space R\&D activities and to represent the Government in relation with ESA, EU (FP Committees, INSPIRE, Copernicus, GNSS), UNCOPUOS, GEO and other organizations.

The new strategy is defined today as the 3S (Science and Technology/Services/Security) and includes the industrial development and the access to space as materialization of the trend of space sector (Piso, M-I., 2019). Since 1995 ROSA followed the necessary steps for a progressive integration in ESA. This key fact, concluded in 2011, defined Romania as the second East European country admitted to this important intergovernmental organization. The considerable subscription for the ESA's EO programme demonstrates the capacity of Romanian entities to compete at the compulsory highest level for the development of satellite missions.

In this context, the EO was considered as a main development axis included in official R\&D national strategy, keeping the synergy with the evolutions of programmes developed by ESA and EC (e.g. COPERNICUS and GALILEO). The Programme for Research-Development-Innovation on Space Technology and Advanced Research - STAR for the 2012-2019 period, approved by Law no. 262/2011, as main instrument of the Ministry of Education, Research, using Romanian Space Agency (ROSA) as managing organization to provide national support for the implement of the Agreement between Romania and European Space Agency (ESA) regarding the Romania's Accession to ESA Convention.

The ROSA Research Center (RRC), organized in 1998, has joined all research capacities in a unique management being involved in partnerships with other Governmental bodies for the implementation of very important projects based on EO/RS technologies.

\section{INSTITUTIONAL OPERATIONAL SUPPORT PROJECTS}

The socio-economic changes started in 1990 generated a new important period for the development of operational Remote Sensing in Romania. Operational applications for agriculture become reality by the setup of the Romanian Center for Remote Sensing Apply (CRUTA), based on the implementation of coherent projects in cooperation with the Joint Research Center of the European Union and CNES (Badea., A., 2015) Started in 1992 with small pilot applications and concluded in 1998 at country level, the Romanian Crop Information System (CIS) transferred the European knowhow for adaptation and fully implementation of the EU-MARS (Monitoring Agriculture by Remote Sensing; today Monitoring Agricultural Resources) methods.

The "Crop Information System" project was developed during the implementation of the major structural modification of Romanian agriculture generated by the implementation of Land Distribution. These changes generated in very short time an 
excessive fragmentation of agricultural fields and increased the number of land owners from about 3,000 to $4,000,000$. It was necessary to create and implement a modern system able to provide reliable information for the Ministry of Agriculture (Figure 1)/

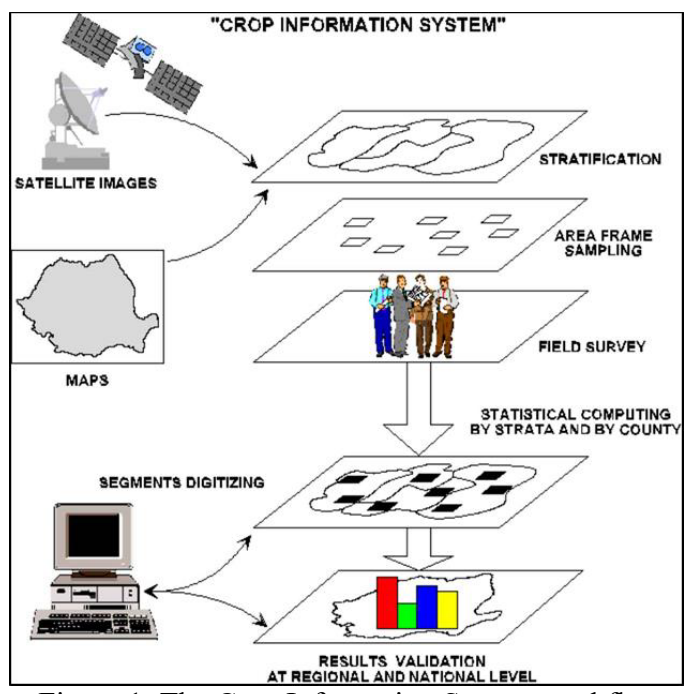

Figure 1. The Crop Information System workflow

The MARS programme evolution as next step for the insertion of the Common Agricultural Policy (CAP) in each European Union member or candidate state includes the setup of the geospatial IACS/LPIS/CwRS system supporting the distribution of subsidies for the agricultural areas declared by the farmers applying for EU and National subsidies (Badea, A., 2015, Docan, D., et al., 2007).

The creation of the Romanian LPIS/IACS system started with pilot projects performed by ROSA and CRUTA joint team in view of evaluation of data sources for creating the geographical database (old aerial photo vs. VHR satellite images)

These subsidies are granted in the framework of the Integrated Administration Control System (IACS), Land Parcel Identification System (LPIS) and the Control with Remote Sensing (CwRS) in accordance with European regulations. The system is based on the geographical plot location principle. Farmers, listed in the official records, have to declare the area of their different cultivated crops to receive European and/or national subsidies (Varteiu, D.P., 2019).

Together with a control system, using VHR satellite images, orthophoto and GNSS ground tracking verifying these declarations that precisely relies on the geographical parcel location the system has been tested and implemented at institutional level at the Agency for Payments and Intervention for Agriculture (APIA).

A complementary action, supporting the LPIS/IACS concept too, was the creation of the FAO-LCCS database in the framework of Land Use/Land Cover Mapping of Romania for the Ministry of Agriculture. According to FAO, land cover is one of the most important elements for description and study of the environment, the easiest detectable indicator of human interventions on the land, a critical parameter for environmental databases, an indicator for landscape changes quickly over time
(Figure 2) and the basic geographic feature that environmental applications can use as reference (Jansen, L., et al.2014).

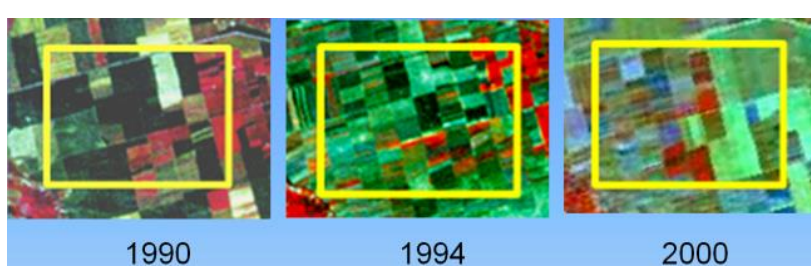

Figure 2. The dynamics of the agricultural landscape in the Romanian Plain

Land Cover Classification System LCCS, based on the FAO concept, offers the possibility to follow the dynamics of the landscape. Major rapid changes of the parcel structure generated errors in the elaboration of strategies for agricultural development.

This objective method tested with good results as basis of analysis in different domains remains a priority for future developments (e.g. production of land cartography, creation of geographic information systems on agro-environmental issues at local and national scales, for public and private institutional clients.

MAES-DSS/Mapping and Assessment of Ecosystems and their Services-Decision Support System (N4D) with the National Environment Protection Agency (NEPA). The methodologies used to implement the N4D project started with the setup of the conceptual framework and continued with the development of methodologies used for policy analysis, mapping and assessment of ecosystems and ecosystem services as well as the monetary and non-monetary assessment. The development and implementation of the Decision Support System (DSS) as a geospatial application allows to query the database on ecosystems and ecosystem services, view maps and facilitate for decision and policy makers to develop, generate different scenarios in connection with the consequences arising from the specific interventions of humans on the state of an ecosystem and the Ecosystem Services that it provides (Bodescu, F., et al., 2017).

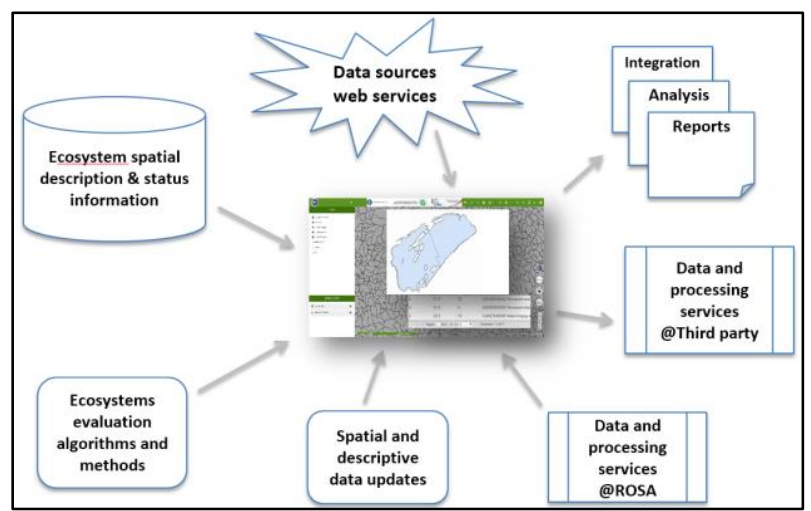

Figure 3. N4D-Decision Support System (DSS) concept

The project Technical Assistance to Develop Romanian Environmental related GIS maps / PHARE project RO 2005/017-553.03.03.04.01 ROEnvGISmap for the constitution 
of the vector and raster basic layers and the geoportal of the Ministry of Environment realized in the framework of EU Phare program had as main goal the production of thematic harmonized data keeping in mind the EU regulations for ensuring the interoperability between the interior (local, regional, national) and EU levels.

More than 50 datasets were provided for the operational use of the Ministry of Environment. Considering the implementation of the INSPIRE directive, the ROEnvGeoPortal offered, for the first time, a wider access to geographic data and services, serving as a catalyst for advancing Spatial Data Infrastructure (SDI) activities in Romania.

The implementation allows users with a set of tools to easily discover, query, and access information on geospatial data holdings and Web services, including the ability to interactively display and query the data and services.

After the deployment of the operational ROEnvGeoPortal environmental public organizations at national, county and local level, become the beneficiaries of a modern tool including maps: with general content to ensure the coherent topographic support, for Nature Conservation Sector, for Industrial Pollution Sector, for Air Quality and Noise, for Waste Management Sector and for Water Quality Sector

The implementation of the projects mentioned above was possible grace of a very confident partnership with experts working for important national and international organizations (e.g. UN-FAO, EC-JRC, ESA, CNES). It was possible to adapt the local experience taking into account the opinion of external advisors and to understand that Remote Sensing is a work for multi-thematic teams (Badea, A., 2015).

\section{SCIENTIFIC PROJECTS}

The capacity building accomplishments were possible since the basic research in EO was oriented at developing innovative methods capable to exploit the satellite imagery. During the period 2000 -2001, as partner of French Space Agency CNES, in the framework of the project Assimilation of Spatial Data within Agriculture Models-ADAM, it was possible to contribute to the development of new way for exploiting high temporal frequency SPOT satellite data, acquired during a phenological crop season for calibration and validation of several agro-physiological models (Lauvernet et al., 2002)

This Franco-Romanian partnership which provided a complete synergic scientific database of remote sensing and ground data products, was taking into account the soil and climate peculiar conditions for the South Băragan Plain. Since its creation, this database is considered as a reference for the experts working with multi-temporal VIS/IR/Radar time series of images, validated with detailed in-situ measurements. The database, the results and the conclusions are freely accessible to the international scientific community and are widely used for the characterization of the soil and the canopy and their functioning mechanisms.

\section{NATIONAL FOUNDED R\&D PROJECTS}

Other core projects, developed in Romania as applied support for implementing COPERNICUS initiatives are examples of good practices for including EO technologies in the field of agroenvironment.

The project called Core COPERNICUS infrastructure for a national geospatial advisory system for irrigated perimeters (GEOFARM) sought to demonstrate how research, technology and innovation can contribute to increasing opportunities to improve the management of irrigated agricultural exploitations. It also looked for the best ways to strengthen the sustainability of local food production by generating a controlled management of water resources in irrigation systems.

It analysed the need to increase food production while respecting sustainable development and focusing on market and competitiveness issues.

The implementation of the project was performed between 2004 and 2007 by a consortium led by the Romanian Space Agency (ROSA). Other partners involved were: The University of Agronomic Sciences and Veterinary Medicine of Bucharest (USAMVB), UTI Grup S.A., Tradsym Consult S.R.L. and the Institute of Agricultural Economics of the Romanian Academy.

The general objective of this project was to establish new and innovative COPERNICUS service capacities for the user community of the irrigation water management system in Romania with the vision of connecting and integrating sustainable food production with equitable economic competitiveness within intelligent scenarios of water governance to prevent conflicts in water-scarce areas.

To reach this general objective, four specific objectives were established and achieved:

1. User communities: Local user communities benefited from the tools developed within the project, which strengthened the capacity for efficient management of irrigated agricultural land.

2. Copernicus-assisted instrument sets: The COPERNICUS tools and services developed under the project have improved the planning, management and control of water used for irrigation.

3. Validated services scenarios: Within the project, preoperational services based on COPERNICUS remote sensing data were developed and validated for the water resources management community in the Brăila - Cazasu area.

4. Business community and sustainable implementation of the project: The technical tools and thematic information developed within the project facilitate the development of local collaborative micro-networks providing services and presenting aspects that stimulate other economic entities by creating an environment favourable to their development for the next period.

The following enumerated projects are not described in this paper, but it is necessary to mention the outputs which constitutes a data support for other developed. Applications: MUTER (Land monitoring core services and applications), GEODIM (Platform for Geoformation in Support of Disaster Management), LCCS07 (Hybrid method for thematic update of the land use inventory by remote sensing/GIS technology) and GEOMORF (Complex method of elaborating the digital geomorphologic map of Romania by means of GIS/RS technologies). 


\section{EDUCATION ACTIVITIES}

Based on the joint venture agreement concluded with the Romanian Centre for Remote Sensing Applications in Agriculture (CRUTA), a more complex partnership with the University of Agronomic Sciences and Veterinary Medicine of Bucharest (USAMVB) was established. Based on the complementarities of infrastructures and the multi-thematic skills of the experts involved, one of the main actions, permanently promoted and performed, is related to the involvement of the staff in educational activities at different levels: primary, secondary schools and universities.

The Basic EO courses of RS (VIS/IR), Radar RS, GNSS, Satellite Mapping and the newly introduced subject Programmes and Applications on Earth Observation are performed by the ROSA's Research Centre experts offering the possibility to the students to connect with the latest knowledge at international level. The last listed course was elaborated in view of initiating the young generation regarding the framework of space activities. Various complementary aspects are composing the complex functional system: regulatory organizations (e.g. UNOOSA, COPUOS/UNSPIDER), national and international operational agencies (e.g. ROSA, CNES, NASA, JAXA, and ESA), international policy and strategy initiatives (e.g. GEO/GEOSS, UN-SDGs) and national and international professional organizations (e.g. ISPRS and national RS associations, like Romanian Society for Photogrammetry and Remote Sensing - (SRFT).

The experience of this team, (professors, researchers and experts) is highlighted also in the framework of the ERASMUS+/GEOMAG project, having as main objective to strengthen capacity in Geomatics applied to agriculture and the environment in Tunisia to better organize the geomatics sector, particularly with regard to the provision of graduate training and continuing education especially in the agricultural sector and the environment.

\section{EDUCATION AND R\&D COMMON ACTIVITIES}

The partnership ROSA-USAMVB is also oriented at performing studies and implementing research projects within national and international programmes. The EC FP6, FP7 and H-2020 calls offered the possibility to establish strong partnerships with organizations from other EU countries. The recently concluded project H2020-EO-2016-DIANA, Following another successful one (FP7-SIRIUS), aimed to develop an EO-based service for water managers for the detection and management of nonauthorized irrigation water abstractions including a drought forecasting and monitoring component.

DIANA project was dedicated to the implementation of a commercial service platform based on Copernicus data collected over three years that help authorities to identify non authorized water abstraction for irrigation. ROSA has been involved in the Banat pilot site deployment for surface soil moisture estimation and illegal water abstraction detection. The researches have been conducted in two directions: analysis of the temporal pattern of the Sentinel 1 SAR sensor response to estimate volumetric soil moisture (Wagner et all, 1999b; Wagner et all, 2008; Wagner et all, 2009) and monitoring of seasonal patterns of changes in leaf area index (LAI) or vegetation indices such as NDVI (Normalized Differential Vegetation Index) and NDWI (Normalized Differential Water Index) for the detection of irrigated areas. Volumetric soil moisture was overestimated due to particularities of the test site: a former swamp developed for agriculture which, depending on the rainfall regime, causes the increase of the ground water level near the surface (between 0.4$4 \mathrm{~m}$ ). Since no a priory information was considered, the performance of the surface soil moisture estimation was assessed as a function of NDWI, NDVI and SAR acquisition far from a rainy episode or in the context of high air temperature recorded (Table 1)

\begin{tabular}{|c|c|c|c|c|c|c|}
\hline \multirow{2}{*}{ Crop type } & $\begin{array}{c}\text { Correlation } \\
\text { Sigma M }\end{array}$ & $\begin{array}{c}\text { Correlation } \\
\text { SSM NDVI }\end{array}$ & $\begin{array}{c}\text { Correlation } \\
\text { Sigma - SSM }\end{array}$ & $\begin{array}{c}\text { Correlation } \\
\text { SSM -NDVI }\end{array}$ & $\begin{array}{c}\text { Correlation } \\
\text { Sigma - SSM }\end{array}$ & $\begin{array}{c}\text { Correlation } \\
\text { SSM -NDVI }\end{array}$ \\
\cline { 2 - 8 } & \multicolumn{2}{|c|}{$\mathbf{2 0 1 7}$} & \multicolumn{2}{|c|}{$\mathbf{2 0 1 8}$} & \multicolumn{2}{|c|}{ 2019 } \\
\hline Winter wheat & 0.78 & 0.65 & $\mathrm{x}$ & $\mathrm{x}$ & 0.8 & 0.1 \\
\hline Rapeseed & 0.72 & 0.57 & 0.6 & 0.1 & $\mathrm{x}$ & $\mathrm{x}$ \\
\hline Soybeans & $\mathrm{x}$ & $\mathrm{x}$ & 0.97 & 0.66 & $\mathrm{x}$ & $\mathrm{x}$ \\
\hline Maize & $\mathrm{x}$ & $\mathrm{x}$ & 0.75 & 0.45 & 0.86 & 0.8 \\
\hline Sorghum & $\mathrm{x}$ & $\mathrm{x}$ & 0.95 & 0.72 & $\mathrm{x}$ & $\mathrm{x}$ \\
\hline Sunflower & $\mathrm{x}$ & $\mathrm{x}$ & 0.92 & 0.65 & 0.88 & 0.84 \\
\hline Alfalfa & $\mathrm{x}$ & $\mathrm{x}$ & 0.7 & 0.2 & 0.8 & 0.3 \\
\hline
\end{tabular}

Table 1. Volumetric soil moisture evaluation based on SAR sensor response and NDVI

The crop water requirements products were processed using TONI pbp software, provided by University of Castilla - La Mancha (UCLM). The software automatically interpolates the gaps between the missing images and by doing so, it completes the vegetation curve with NDVI values for every each day. The results are rasters with crop water requirements for every pixels.

The combination of agrometeorological data and models with vegetation indices allow as to estimate the abstracted volumes of water for irrigation purposes (Calera et all, 2017, Vanino et all, 2015). Table 2 . shows the differences between water volume declared by farmers and gross irrigation water requirements (GIWR) calculated from the time series of satellite images. These results encourage Romanian authorities to use products based on EO data in detection of non-authorized water abstraction.

\begin{tabular}{|c|c|c|c|c|c|c|}
\hline \multirow{2}{*}{ Crop } & $\begin{array}{c}\text { Surface } \\
\text { (ha) }\end{array}$ & $\begin{array}{c}\text { Irrigation quantity } \\
\text { declared by farmer } \\
\text { (mm) }\end{array}$ & $\begin{array}{c}\text { GIWR } \\
\text { (mm) }\end{array}$ & $\begin{array}{c}\text { Surface } \\
\text { (ha) }\end{array}$ & $\begin{array}{c}\text { Irrigation quantity } \\
\text { declared by farmer } \\
\text { (mm) }\end{array}$ & $\begin{array}{c}\text { GIWR } \\
\text { (mm) }\end{array}$ \\
\cline { 2 - 7 } & \multicolumn{5}{|c|}{$\mathbf{2 0 1 8}$} & \multicolumn{4}{|c|}{$\mathbf{2 0 1 9}$} \\
\hline \multirow{2}{*}{ Maize } & 309 & 20 & 82 & 308 & 60 & 269 \\
\cline { 2 - 7 } & 309 & 20 & 59 & 308 & 56 & 264 \\
\hline \multirow{2}{*}{ Sunflower } & $\mathrm{x}$ & $\mathrm{x}$ & $\mathrm{x}$ & 100 & 40 & 233 \\
\cline { 2 - 7 } & $\mathrm{x}$ & $\mathrm{x}$ & $\mathrm{x}$ & 100 & 29 & 170 \\
\hline
\end{tabular}

Table 2. Gross irrigation water requirement retrieved based on Sentinel-2 data

The FP 7 SIRIUS project was contributed to the development of the water resource management services in support of food production in water scarce environment, including drought management. The technical core of all SIRIUS Services was the webGIS SPIDER platform (System of Participatory Information, Decision-support, and Expert knowledge for River-basin management), powered by EO imagery, non-EO data and multimedia. SPIDER it is a powerful tool for stakeholder participation, collaboration and transparent governance which help authorities make decisions to improve agroforestry environments at different levels of management.

There was first Romanian involvement in such kind of services linked with national strategy for irrigation: "improving the efficiency of irrigation water use at farmer level". The water 
related challenge consisted in solving the water conflicts between old and new irrigation schemes and fast industrial development.

The main goals were facilitating the access of farmers to satellite information regarding irrigation water requirements and training the farmers for accessing and using this information via computer. SIRIUS was addressed to farmers and Irrigation Water Users Associations (IWUA) from the Cazasu, Braila County. Only big farmers could implement the SIRIUS results because they operated and used the majority of irrigation infrastructure, had good GIS skills and good farming skills.

The collaboration is not limited to pure agro-environmental subjects. The ongoing Multidisciplinary complex project for the monitoring, conservation, protection and promotion of the Romanian cultural heritage (RO-CHER) is largely based on the combined use of various technologies, including EO, for the development of methodologies and materials meant to integrate the research dedicated to the study of the mobile and immobile cultural and historical heritage. This also integrates activities for assessment of environment conditions for cultural heritage sites.

The RO-CHER project proposes a multidisciplinary methodology for the monitoring, conservation, protection, and promotion of the Romanian cultural heritage. RO-CHER project integrates high-level scientific knowledge for safeguarding the cultural heritage and its main goal is the development of synergetic scientific activities in the framework of the 4 complementary component projects by monitoring the $\mathrm{CH}$ objectives with the aid of space technologies; development of materials and innovative techniques based on soft nanomaterials for safeguarding the cultural heritage; recommendation of an integrated management system (conservation, restoration, protection) for mobile and immobile $\mathrm{CH}$ objectives; promoting $\mathrm{CH}$ by using state-of-the-art technologies of digital reconstruction.

The project, led by the Romanian Space Agency (ROSA), started in 2018 and will end in 2021. Until now, two phases have concluded. The project uses a multi-stage approach (with four research projects) and generates products, technologies and strategies for the integrated conservation of the movable and immovable cultural heritage. Other partners in the consortium are: The University of Agronomic Sciences and Veterinary Medicine of Bucharest (USAMVB), the National Institute for Research \& Development in Chemistry and Petrochemistry (ICECHIM), the National Museum of Unification Alba Iulia (MNUAI) and the Museum of Dacian and Roman Civilization (MCDR).

Within Project 1, Monitoring of cultural heritage based on space technologies, the objectives representative of the Romanian cultural heritage were identified and analysed, subsequently being determined different optimal methodologies of satellite monitoring and selecting the types of satellite recordings for the generation of the final products. For the identified objectives, satellite images were acquired in order to obtain geospatial products, different techniques being used for multitemporal monitoring of cultural objectives such as analyses of vegetation indices, analysis of multitemporal evolution, Persistent Scatterer Interferometry (PS-InSAR) monitoring to identify millimetre displacements of terrain and buildings, risk mapping and GNSS for validating the results.
In order to obtain three-component recipes by various methods and to establish an optimal ratio for a maximum antimicrobial effect, the multidisciplinary team of Project 2, Nanotechnology an innovative approach of developing materials and methods for cultural heritage safeguarding, optimized the recipe for obtaining soft nanomaterials.

Integrated cultural heritage management (conservation, restoration, and protection), is the third component project that has identified the degradation phenomena for both cultural heritage objects and archaeological objectives. Standard working procedures have been developed for the management of mobile cultural heritage (for the implementation of various conservation and restoration measures) and for the management of immobile cultural heritage (for obtaining complementary information using geospatial information).

In order to preserve and promote these cultural heritage objects and objectives, through the Project 4, Cultural heritage promotion based on modern digital reconstruction technologies, the appropriate scanning methodologies for the objectives were chosen, and the optimal processing flows for them were developed. Finally, structured light scanner sessions of exhibits and aerial scanning with Light Detection and Ranging sensor campaigns have taken place. With their input, digital 3D models have been realized which will be promoted in the next stage. The results of the project will support the national and local authorities responsible for the protection of cultural heritage.

\section{FINAL REMARKS}

This paper illustrates how a coherent national multi-disciplinary space programme stimulates the progress in the agriculture and environment sectors, having as main support the R\&D and educational activities.

\section{ACKNOWLEDGEMENTS}

This work was supported by a grant of the Romanian Ministry of Research and Innovation, CCCDI - UEFISCDI, within PNCDIIII, project number PN-III-P1-1.2-PCCDI-2017-0413/contract number 50PCCDI/2018.

This work was also supported under the project "Demonstrating and promoting natural values in support of decision-making processes in Romania - Nature4Decision-Making-N4D", financed by a grant from Iceland, Liechtenstein and Norway (EEA 2009 - 2014) within the RO02 Program - Biodiversity and Ecosystem Services, for which the Ministry of Environment is a Program Operator.

\section{REFERENCES}

Badea, A., 2016: Land Remote Sensing in Romania. http://seom.esa.int/landtraining2015/files/Day_1/3_LTC2015_L andRSRomania_Badea.pdf

Badea, A., 2019: GEOMAG: an ERASMUS+ project, UN/Romania International Conference on Space Solutions for Sustainable Agriculture and Precision Farming. https://www.unoosa.org/documents/pdf/psa/activities/2019/UN Romania2019/UNRomania_Presentations/3._GEOMAG_an_E RASMUS_PLUS_project_in_Tunisia_2.pdf 
Bodescu, F., et al., 2017: Assessment of Ecosystems and Ecosystem Services in Romania. NEPA, NINA, ROSA, WWF Romania, ISBN 978-606-8038-23-0

Bodescu, F., et al., 2017: MAES process in Romania -Nature for decision-Making (N4D), NEPA, NINA, ROSA, WWF Romania, ISBN 978-606-8038-24-7

Calera, A.; Campos, I.; Osann, A.; D’Urso, G.; Menenti, M., (2017): Remote Sensing for Crop Water Management: From ET Modelling to Services for the End Users. Sensors, 17, 1104

Docan, D. C., Dana, I., Badea, A., Moise, C., \& Badea, R. (2007). Adapted methods of spatial information analysis developed and implemented in the framework of IACS-LPIS setup in Romania. p.231-232, Annals of DAAAM for 2007 \& Proceedings of the 18th International DAAAM Symposium, ISBN 3-901509-58-5, ISSN 1726-9679, pp 117, Editor B. Katalinic, Published by DAAAM International, Vienna, Austria 2007

Lauvernet, C., Le Dimet, F.X., Baret, F., Deboissezon, H., Favard, J.C., Vintila, R., Lazar, C., Badea, A., 2002: Assimilation of high temporal frequency SPOT data to describe canopy functioning - the case of wheat crops in the ADAM experiment in Romania. Sobrino José Antonio editors, Auditori de Torrent, Espagne, Recent Advances in Quantitative Remote Sensing, RAQRS, ISBN: 8437055156/9788437055152

Jansen, L., Badea, A.; Milenov, P.; Moise, C.; Vasiliev, V.; Milenova, L.; Devos, W. (2014), The use of the Land-Cover Classification System in Eastern European countries: experiences, lessons learnt and the way forward, chapter in book: Land use and land cover mapping in Europe: practices and trends, Remote Sensing and Digital Image Processing - Volume 18 edited by Ioannis Manakos, Matthias Braun, 03/2014: pages 297-325; Springer Verlag., ISBN: 978-94-007-7968-6 (Print) 978-94-007-7969-3
Niculescu, S., Philippe Fournier, Ph., Badea, A., (2014): Area sampling and information systems applied to land-cover and land-use. Case study: post-communist Romania, Revue Française de Photogrammétrie et de Télédétection, vol. 205, 2014/1/10, 35-47

Piso, M-I., 2019: Space as Enabler. UN-OOSA web resources https://www.unoosa.org/documents/pdf/psa/activities/2019/UN Romania2019/UNRomania_Presentations/2._ROSA_SSS_UN_ Cluj_MAY_2019_v1_Short.pdf

Vanino, S.; Nino, P.; De Michele, C.; Bolognesi, S.F.; Pulighe, G., (2015) Earth Observation for Improving Irrigation Water Management: A Case-study from Apulia Region in Italy. Agric. Agric. Sci. Procedia, 4, 99-107

Varteiu, D.P., (2019): Agency for Payments and Intervention for Agriculture - Agency which Manages the Funds Destined to Agriculture, "Ovidius" University Annals, Economic Sciences Series Volume XIX, Issue $1 / 2019$

Wagner, W., Noll, J., Borgeaud, M., Rott, H. (1999): Monitoring soil moisture over the Canadian Prairies with the ERS Scatterometer, IEEE T. Geosci. Remote, 37, 206-216, doi: $10.1109 / 36.739155, \mathrm{~b}$

Wagner, W., Pathe, C., Doubkova, M., Sabel, D., Bartsch, A., Hasenauer, S., Bloschl, G., Scipal, K., Martinez-Fernandez, J., and Low, A., (2008): Temporal stability of soil moisture and radar backscatter observed by the Advanced Synthetic Aperture Radar (ASAR), Sensors, 8, 1174-1197, doi:10.3390/s8021174

Wagner, W., Sabel, D., Doubkova, M., Bartsch, A., and Pathe, C., (2009): The potential of Sentinel-1 for monitoring soil moisture with high spatial resolution at global scale, in: Symposium of Earth Observation and Water Cycle Science, 